\title{
Use of discount cigarettes by smokers in 20 communities in the United States, 1988-1993
}

K Michael Cummings, Andrew Hyland, Eugene Lewit, Don Shopland

\begin{abstract}
Objective-To examine characteristics of smokers associated with the use of discount and generic cigarettes.

Design-Data for this analysis come from two population-based cross-sectional telephone surveys (1988 survey $n=32$ 952; 1993 survey $n=11783$ ) and $a$ cohort tracking survey $(n=11966)$ of smokers aged 25-64 years conducted in 20 communities in the United States between 1988 and 1993 as part of the National Cancer Institute's Community Intervention Trial for Smoking Cessation.
\end{abstract}

Outcome measures-In each survey, current smokers were asked to report the six-digit UPC code displayed on the side of the pack of their current cigarettes. Respondents who did not have a pack available or who could not locate the UPC code number were asked to report their usual brand of cigarettes smoked. A master list of UPC code numbers was developed so that reported UPC codes could be associated with specific cigarette brand names. Brand name cigarettes were categorised as either premium or discount brands using information from the Maxwell consumer report. Respondents who reported smoking "no name" generic cigarettes were classified as smoking a discount cigarette.

Results-The reported use of discount/ generic cigarettes increased from $6.2 \%$ in 1988 to $23.4 \%$ in 1993 . The trend toward increased use of lower priced cigarettes

Department of Cancer Control and

Epidemiology, Roswell Park Cancer Institute, Buffalo, New York, USA

K M Cummings

A Hyland

Center for the Future of Children, Los Altos, California

E Lewit

Smoking and Tobacco Control Program, National Cancer Institute, Rockville, Maryland

D Shopland

Correspondence to: Dr K Michael Cummings, Department of Cancer Control and Epidemiology, Roswell Park Cancer Institute, Elm and Carlton Street, Buffalo, New York 14263, USA; email:

mcummings

@sc3102.med.buffalo.edu
Introduction

It is well recognised in economic theory, as well as in everyday life, that purchasing decisions are influenced by price.' Because of the addictive qualities of tobacco, some researchers have speculated that consumption of cigarettes is insensitive to price changes. ${ }^{2}$ However, studies have repeatedly found that consumption of cigarettes goes down when the real price increases. ${ }^{3}$ Some studies suggest that the effect of price changes may vary depending on the smoker's level of addiction and disposable income. ${ }^{24}$

During the first 30 to 40 years of this century, there were a number of low-priced brands, and roll-your-own cigarettes were a popular form of consumption. ${ }^{5}$ Roll-your-owns were the lowest priced form of cigarette consumption. Over time, as personal income rose, there was a tendency to substitute premium brands for both the lower priced brands and roll-your-owns and the lower priced options virtually disappeared from the market. The tradition of uniformity in prices across brands was broken in 1980 when Liggett, the smallest American cigarette maker, launched the first price-value cigarette. ${ }^{6}$ Sales of Liggett's plain and private label cigarettes took off and within a couple of years all the cigarette manufacturers had introduced low-priced brands. Beginning around 1985 and lasting up until 1993, the cigarette market could be divided into three different pricing categories: full-priced or premium brands, branded discount cigarettes representing a middle pricing tier (about $20-25 \%$ off the price of a typical premium brand), and sub-discount and generic brands which were the lowest price category (about $40-50 \%$ off the price of a typical premium brand). ${ }^{6}$ By the the price of a typical discount and generic cigarettes accounted for over $37 \%$ of unit sales. ${ }^{7}$

The availability of low-priced cigarettes has important implications for tobacco control. important implication prices makes consumption more affordable, which may help boost or at least maintain consumption among current smokers and help retain smokers who might otherwise quit cigarettes altogether. ${ }^{8}$ Consequently, some groups have called on federal and state governments to increases cigarette taxes to offset the increased affordability of cigarettes so as to maintain an economic disincentive to smoke. ${ }^{910}$

Despite the dramatic growth in price value segment of the cigarette market over the past segment of the cigarmation is available in the public health literature on the characteristics of
Keywords: generic cigarettes; cigarette pricing policies; cigarette smoking behaviour 
people who use discount cigarettes. This paper uses data gathered as part of the National Cancer Institute's Community Intervention Trial for Smoking Cessation (COMMIT) study to examine the reported use of branded discount and generic cigarettes among smokers in 20 communities in the United States between 1988 and 1993.

\section{Methods}

\section{COMMIT STUDY}

The COMMIT study was a randomised, contholled trial conducted at the community level to test the effectiveness of a multi-faceted intervention to help smokers achieve and maintain cessation. The study involved 11 matched pairs of communities: 10 paired communities in the United States and one pair in Canada. Within each community, the smoking habits of the population were monitored over a five-year period between 1988 and 1993. The design and primary outcomes of the COMMIT study have been described previously. ${ }^{11-19}$

DATA COLLECTION

The data come from two population-based, cross-sectional telephone surveys conducted in the 20 American COMMIT communities in 1988 and 1993, and from a cohort tracking survey of cigarette smokers followed between 1988 and 1993. Each of these surveys have been described in detail elsewhere and are summarised only briefly here. ${ }^{12-14}$ Data from the two Canadian communities in COMMIT were excluded from this analysis as discount and generic cigarette brands are not widely available in Canada.

From January to May 1988, a telephone survey was conducted to estimate baseline prevalence and identify cohorts of smokers within each of the following communities: Bellingham and Longview/Kelso, Washington; Albany/Corvallis and Medford/Ashland, Oregon; Vallejo and Hayward, California; Santa Fe and Las Cruces, New Mexico; Cedar Rapids and Davenport, Iowa; Raleigh and Greensboro, North Carolina; Paterson and Trenton, New Jersey; Lowell and Fitchburg/Leominster, Massachusetts; and Yonkers, New Rochelle, Utica, and Binghamton/Johnson City, New York. The survey was conducted centrally using a modified, random-digit dialling technique with community-specific geographic screening to identify households within the targeted areas. Baseline survey data were collected in two stages. The first stage involved identifying representative samples of approximately 5400 households within each community and gathering information on the age, gender, and smoking habits of all adults within selected households. A sample of this size was chosen to obtain the required number of smokers to form cohorts to be followed over the next five years. In the second stage, a sample of current smokers aged 25-64 years was selected for an extended interview, which included questions about current and past smoking habits, brand and type of cigarette usually smoked, interest in quitting smoking, and sociodemographic characteristics. Current having smoked at least 100 cigarettes in their lifetime and who reported smoking at the present time. The mean response rate for the household rostering portion of the survey was $82.8 \%$. Of the eligible smokers identified from the household rostering, $86.0 \%$ completed an extended interview. Overall, the baseline prevalence survey gathered data on 32952 current smokers aged 25-64 years; cigarette brand preference information is available on $32049(97.3 \%)$ of the current smokers interviewed.

A second prevalence survey was conducted from August 1993 to January 1994 in the same communities as the 1988 baseline survey. The sampling method and procedures used for the second prevalence survey were analogous to those used in the baseline survey, although the second survey was not as large, involving approximately 2300 households per community. In this survey, all those of 18 years of age and older were rostered by a proxy who provided information on their age, sex, and smoking status. Current smokers aged 25-64 years participated in an extended interview to gather information on current and past smoking status, brand and type of cigarette usually smoked, methods used to try to quit smoking, and sociodemographic information. The mean response rate for the household rostering portion of the second prevalence survey was $72.3 \%$. The response rate for the extended interview portion of the survey was $80.2 \%$. The second prevalence survey includes data on 11783 current smokers aged 25-64 years; cigarette brand preference data is available on $11546(98.0 \%)$ of these smokers.

The 1988 prevalence survey was used to identify a cohort of approximately 915 current smokers aged 25-64 years in each community who could be followed prospectively until 1993 (total cohort size $=18332$ ). . Cohort members were not explicitly notified of their status as cohort members. However, respondents were informed that they would be contacted annually. Between 1989 and 1992, cohort participants were contacted once a year by either telephone or mail to assess their smoking status and residency. Between January and May 1993, cohort members were asked to respond to a more detailed telephone interview that included questions about current smoking status, brand and type of cigarette usually smoked, and efforts made to stop smoking during the preceding five years. Cohort members who reported that they no longer smoked cigarettes were asked to indicate when they quit smoking and why. At the final annual contact, cohort members who declined to be interviewed were asked if they would respond to an abbreviated set of questions about their smoking status. Members who could not be reached by phone were also mailed these same questions. These methods yielded data on current smoking status from an additional $6.7 \%$ of cohort participants. Overall, $65.3 \% \quad(n=$ $11966)$ of cohort members provided information on their smoking status at the final contact 
in 1993. Reasons for non-response were, in order of importance, unable to locate $(30.6 \%$, $\mathrm{n}=5607)$, respondent deceased $(2.5 \%, \mathrm{n}=$ $463)$, and respondent refusal $(1.6 \%, \mathrm{n}=296)$.

Among the 11966 cohort members who participated in the final follow-up interview, $8201(68.5 \%)$ reported themselves to be current smokers in 1993. Among current smokers in $1993,7081(86.3 \%)$ provided cigarette brand information in both the 1988 and 1993 surveys.

Measurement of cigarette brand used
In each survey, current smokers were asked to In each survey, current smokers were asked to listed on the side of their current pack of cigarettes. Respondents who did not have a pack available or who could not locate the UPC code on their current pack were asked to give the name of the cigarette brand they usually smoke. We developed of list of 100 cigarette brands with their corresponding UPC code so that each respondent's reported UPC code could be linked to a specific cigarette brand.

Respondents were considered to be smoking generic or discount cigarettes if they self-reported smoking a generic brand of cigarettes or if the brand they smoked, identified from the UPC code or from self-report, could be classified as a discounted brand from the Maxwell consumer report. ${ }^{7}$ Table 1 shows the designation of different cigarette brands as either a premium or discount brand as defined for this analysis. Although our coding of cigarette brands as either premium or discount is generally accurate, it does not take into account the repositioning of some brands as either premium or discount, nor does it consider the use of coupons and other economic incentives used to reduce price.

ANALYSIS

Estimates of brand choice by current smokers were obtained separately by year and by community. Data for each community were weighted to reflect variation in sampling fractions and response rates. Results are only presented for the 1993 cross-sectional survey; the 1988 results are available upon request. To evaluate change in the use of premium and price value cigarettes over time, brand choice information from current smokers reported in the 1988 and 1993 cross-sectional surveys were compared. Differences in the use of premium brand cigarettes between 1988 and 1993 were calculated for each community.

To describe smoker characteristics associated with the use of premium or price value cigarettes, data from the 1993 cross-sectional survey were used. The brand of cigarette used (premium or discount/generic) was analysed in relation to the following variables: age, gender, race, educational level, average annual household income, amount smoked daily, and community. Comparisons within groups were made using $\chi^{2}$ tests.

To evaluate factors predictive of use of discount/generic cigarettes, a logistic regression analysis was performed using information collected on the 7081 continuing smokers
Table 1 Classification of cigarette brands as premium or discount*

\begin{tabular}{ll}
\hline Premium brands & Discount brands \\
\hline Barclay & Alpine \\
Belair & American \\
Benson \& Hedges & Austin \\
Camel & Basic \\
Capri & Best Value \\
Carlton & Bristol \\
Chesterfield & Bronsen \\
Craven & Bucks \\
du Maurier & Bull Durham \\
Dunhill & Cambridge \\
Eve & Century \\
Export & Doral \\
Kent & GPC \\
Kool & Magna \\
L \& M & Malibu \\
Lark & Montclair \\
Lucky Strike & Misty \\
Marlboro & Monarch \\
Max & Multifilter \\
Merit & Old Gold \\
More & Prime \\
Newport & Private Stock \\
Now & Pyramid \\
Pall Mall & Rainbow \\
Parliament & Richland \\
Philip Morris & Riviera \\
Players & Scotch Buy \\
Raleigh & Sterling \\
Rothman & Style \\
Salem & Sundance \\
Saratoga & Viceroy \\
Satin & \\
Silva Thins & \\
Tall & \\
Tareyton & \\
True & \\
Vantage & \\
Virginia Slims & \\
Winston & \\
Man & \\
\hline & \\
\hline
\end{tabular}

Source: year-end brand sales and market share data from Source classified as premium.

tracked as part of the cohort survey. Variables analysed in relationship to the use of discount/ generic cigarettes in 1993 include the following measures obtained in 1988: age, gender, household income, educational level, amount smoked daily, use of discount/generic cigarettes, desire to stop smoking, and quit attempts in the past year. In addition, based on each respondent's community of residence, a measure of the average cigarette price in 1993 was added to the analysis. The measure of cigarette price is a state-level average price taken from the Tobacco Institute's annual Tax burden on tobacco. ${ }^{15}$ This price measure is inclusive of state-level excise taxes on cigarettes and reflects the average price for a pack of 20 cigarettes, based on the prices of single packs, cartons, and vending machine sales, and includes generic cigarettes. To account for differences in the relative cost of cigarettes compared with other goods by area, the real price for each community is divided by the cost of living index assigned for each community. ${ }^{16}$ Cigarettes will be relatively more affordable compared with other goods in locales with a higher cost of living. It is hypothesised that higher cigarette prices will be associated with greater use of discount/generic cigarettes.

In an attempt to get at the question of whether brand choice influences smoking behaviour, a series of logistic regression analyses were also undertaken using the cohort data to predict smoking cessation and amount 


\begin{tabular}{|c|c|c|c|c|c|c|}
\hline \multirow[b]{2}{*}{ Community } & \multicolumn{2}{|c|}{ Sample sizes } & \multicolumn{2}{|c|}{$\begin{array}{c}\text { Premium } \\
(\%)\end{array}$} & \multicolumn{2}{|c|}{$\begin{array}{c}\text { Discount/generic } \\
(\%)\end{array}$} \\
\hline & 1988 & 1993 & 1988 & 1993 & 1988 & 1993 \\
\hline $\begin{array}{l}\text { Hayward, California } \\
\text { Vallejo, California }\end{array}$ & 1662 & 559 & 96.5 & 83.1 & 3.5 & 16.9 \\
\hline & 1663 & 481 & 94.7 & 80.4 & 5.3 & 19.6 \\
\hline & 1337 & 622 & 83.2 & 64.3 & 16.8 & 35.7 \\
\hline $\begin{array}{l}\text { Cedar Rapids, Iowa } \\
\text { Davenport, Iowa }\end{array}$ & 1324 & 693 & 90.1 & 68.3 & 9.9 & 31.7 \\
\hline \multirow{2}{*}{$\begin{array}{l}\text { Lowell, Massachusetts } \\
\text { Fitchburg/Leominster, }\end{array}$} & 1384 & 678 & 97.0 & 78.1 & 3.0 & 21.9 \\
\hline & 1264 & 606 & 95.8 & 71.8 & 4.2 & 28.2 \\
\hline \multirow{2}{*}{ Paterson, New Jersey } & 1982 & 569 & 97.9 & 96.6 & 2.1 & 3.4 \\
\hline & 1862 & 723 & 97.9 & 92.5 & 2.1 & 7.5 \\
\hline Trenton, New Jersey & 1931 & 474 & 92.8 & 76.9 & 7.2 & 23.1 \\
\hline Las Cruces, New Mexico & 2480 & 458 & 96.2 & 81.2 & 3.8 & 18.8 \\
\hline Yonkers, New York & 1578 & 567 & 98.8 & 92.4 & 1.2 & 7.6 \\
\hline New Rochelle, New York & 1667 & 505 & 98.2 & 95.3 & 1.8 & 4.7 \\
\hline Utica, New York & 1428 & 723 & 90.5 & 73.2 & 9.5 & 26.8 \\
\hline \multirow{2}{*}{$\begin{array}{l}\text { Utica, New York } \\
\text { Binghamton/Johnson City, New } \\
\text { York }\end{array}$} & 1400 & 656 & 94.9 & 71.3 & 5.1 & 28.7 \\
\hline & & 667 & 92.9 & 77.1 & 7.1 & 22.9 \\
\hline & $\begin{array}{l}1562 \\
1619\end{array}$ & 496 & 96.1 & 78.0 & 3.9 & 22.0 \\
\hline $\begin{array}{l}\text { Greensboro, North Carolina } \\
\text { Raleigh, North Carolina }\end{array}$ & $\begin{array}{l}1619 \\
1494\end{array}$ & 495 & 91.4 & 58.4 & 8.6 & 41.6 \\
\hline \multirow{2}{*}{$\begin{array}{l}\text { Medford/Ashland, Oregon } \\
\text { Albany/Corvallis, Oregon }\end{array}$} & 1456 & 447 & 89.4 & 65.6 & 10.6 & 34.4 \\
\hline & 1634 & 474 & 94.7 & 73.6 & 5.5 & $\begin{array}{l}34.4 \\
26.4\end{array}$ \\
\hline \multirow{2}{*}{$\begin{array}{l}\text { Bellingham, Washington } \\
\text { Longview/Kelso, Washington }\end{array}$} & 1325 & 639 & 87.1 & 53.0 & 12.9 & 47.0 \\
\hline & 32052 & 11532 & 93.8 & 76.6 & 6.2 & 23.4 \\
\hline
\end{tabular}

*From 1988 and 1993 prevalence surveys.

smoked in 1993 by type of cigarette smoked in 1988 (premium or discount/generic), correcting for demographic variables and baseline level of smoking. The estimated price elasticity of the demand for discount/generic cigarettes

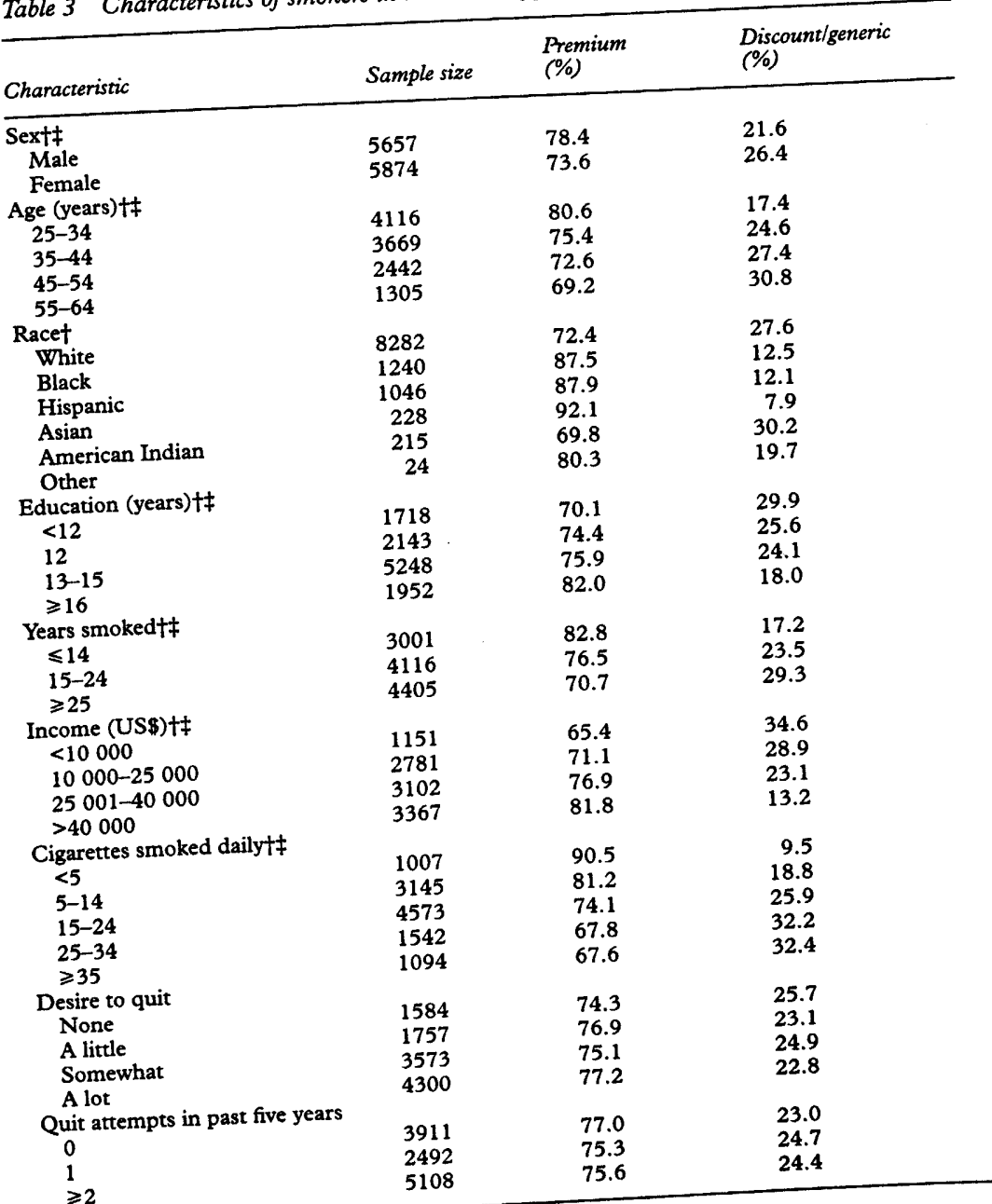

*From 1993 final prevalence survey. From 1993 fer Pen's $\chi^{2}$ test of independence. $+\mathrm{P}<0.001$ for Pearson's $\chi$ test was calculated using the average price and use of discount cigarettes in the sample, as well as the coefficient estimated from the logistic regression model.

Results

Table 2 shows the percentage of current smokers who reported using premium and discount/ generic cigarettes in 1988 and 1993 by community. Between 1988 and 1993, in each of the 20 communities included in our study, the percentage of current smokers who reported using premium cigarettes declined, whereas the number using discount/generic cigarettes increased. Averaged across the 20 communities, the use of premium cigarettes declined by $18.0 \%$ from $93.8 \%$ in 1988 to $76.6 \%$ in 1993 and the use of discount/generic $76.6 \%$ in 1993 and by $271 \%$ from $6.2 \%$ in 1988 to $23.4 \%$ in 1993 .

Table 3 shows the characteristics of smokers in 1993 associated with the use of premium and discount/generic cigarettes. The use of discount/generic cigarettes was more common among women, non-Hispanic whites, those over age 45, people with lower annual household incomes, and heavy smokers.

Figure 1 summarises brand switching behaviour of smokers tracked in the cohort survey between 1988 and 1993. Among those moking a premium brand cigarette in 1988, $77.5 \%$ were still smoking a premium brand cigarette in 1993, whereas $22.5 \%$ had switched to a discount/generic brand. Among those to a discoung a discount/generic cigarette brand in $1988,84.5 \%$ were still smoking a lowpriced cigarette brand in 1993; whereas $15.5 \%$ had switched to a premium brand cigarette.

Table 4 summarises results of our logistic regression analyses examining predictors of the use of discount/generic cigarettes between 1988 and 1993 among continuing smokers tracked in our cohort survey. The average cigarette price in a community was found to have a positive and statistically significant impact on 


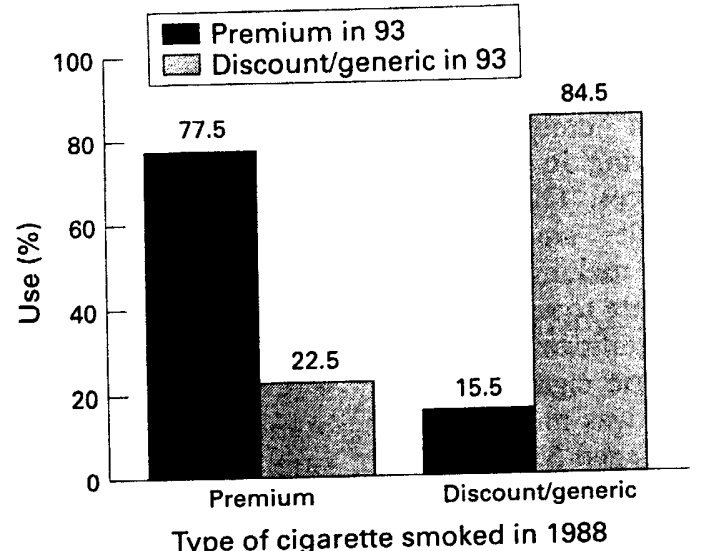

Change in the use of premium and discount/generic cigarettes in a cohort of smokers $(n=7081)$ between 1988 and 1993.

Table 4 Results of logistic regression modelling use of discount/generic cigarettes in $1993^{*}$

\begin{tabular}{|c|c|c|}
\hline Predictor variables & Odds ratio & $95 \% C I$ \\
\hline $\begin{array}{l}\text { Race } \\
\text { White } \\
\text { Black } \\
\text { Hispanic } \\
\text { Asian } \\
\text { American Indian } \\
\text { Other }\end{array}$ & $\begin{array}{l}1.00 \\
0.62 \dagger \\
0.64 \dagger \\
0.88 \\
1.66 \\
0.64\end{array}$ & $\begin{array}{l}\text { Referent } \\
0.46-0.85 \\
0.46-0.88 \\
0.46-1.68 \\
0.95-2.91 \\
0.17-2.44\end{array}$ \\
\hline $\begin{array}{l}\text { Age (years) } \\
25-34 \\
35-44 \\
45-54 \\
55-64\end{array}$ & $\begin{array}{l}1.00 \\
1.09 \\
1.18 \\
0.98\end{array}$ & $\begin{array}{l}\text { Referent } \\
0.94-1.27 \\
1.00-1.40 \\
0.81-1.19\end{array}$ \\
\hline $\begin{array}{l}\text { Education (years) } \\
<12 \\
12 \\
13-15 \\
\geqslant 16\end{array}$ & $\begin{array}{l}1.00 \\
0.99 \\
0.93 \\
0.82\end{array}$ & $\begin{array}{l}\text { Referent } \\
0.81-1.20 \\
0.78-1.11 \\
0.66-1.02\end{array}$ \\
\hline $\begin{array}{l}\text { Cigarettes smoked daily in } 1988 \\
<5 \\
5-14 \\
15-24 \\
25-34 \\
\geqslant 35 \\
\text { Use discount/generics in } 1988\end{array}$ & $\begin{array}{l}1.00 \\
1.27 \\
1.58 \ddagger \\
2.00 \dagger \\
2.36 \dagger\end{array}$ & $\begin{array}{l}\text { Referent } \\
0.81-1.99 \\
1.03-2.44 \\
1.29-3.09 \\
1.51-3.66\end{array}$ \\
\hline $\begin{array}{l}\text { Use discount/generics in } 1988 \\
\text { No } \\
\text { Yes } \\
\text { Average standardised price of cigarettes in } 1993 \\
\text { (US\$) }\end{array}$ & $\begin{array}{l}1.00 \\
15.87 t \\
2.67 t\end{array}$ & $\begin{array}{l}\text { Referent } \\
12.28-20.50 \\
2.15-3.32\end{array}$ \\
\hline
\end{tabular}

^From endpoint cohort data set.

$+\mathrm{P}<0.01$.

$\$ \mathrm{P}<0.05$.

$\mathrm{CI}=$ confidence intervals.

Table 5 Results from regression models examining the effect of the type of cigarette smoked Table 5 Results from regression models examining the effect of the type 1988 on smoking cessation* and daily cigarette consumptiont in $1993 \neq$

in 1988 on smoking cessation * and daily cigarette consumptiont in 199

\begin{tabular}{llllll}
\cline { 5 - 6 } Predictor variable & \multicolumn{2}{c}{ Smoking cessation } & & \multicolumn{2}{c}{ Amount smoked daily } \\
\cline { 2 - 3 } \cline { 5 - 6 } & Odds ratio & $95 \%$ CI & & $\beta$ & $95 \%$ CI \\
\hline Use discount/generics in 19889 & 0.79 & $0.65-0.96$ & & 0.69 & $-0.11-1.49$ \\
\hline
\end{tabular}

*Logistic regression model from the cohort data.

Logistic regression mort

data.

$¥$ Both models control for age, race, income, education,

cigarettes in 1993, and COMMIT intervention status.
U Use of a premium cigarette brand is the reference category.

SUse of a premium cigarette
$\mathrm{CI}=$ confidence intervals. the use of discount/generic cigarettes. The estimated price elasticity of demand for the use of discount/generic cigarettes was 0.978 , which means that a $10 \%$ increase in the price of cigarettes resulted in an estimated $10 \%$ increase in the lower priced cigarettes. ${ }^{.}$Other significant predictors of the use of discount/generic cigarettes included the use of discount/generic cigarettes in 1988, average number of cigarettes consumed daily, and annual household income.

Overall, $31.5 \% \quad(n=3765)$ of cohort members reported not smoking in 1993. Among cohort members who were still smoking in $1993,36.5 \%$ were classified in a lower category $(<5$ cigarettes/day, 5-14 cigarettes/day, etc.) of reported daily smoking in 1993 compared with 1988. Respondents who reported using discount/generic cigarettes in 1988 were 0.79 ( $95 \%$ confidence interval $(\mathrm{CI})=0.65$ to 0.96 ) times less likely to report having quit smoking in 1993 compared with those using premium cigarettes in 1988 (table 5). Among those who reported smoking in both surveys, use of discount/generic cigarettes in 1988 was also associated with smoking more cigarettes per day in 1993, although this difference was not statistically significant at the $\mathrm{P}<0.05$ level.

\section{Discussion}

The results of this study confirm evidence of the dramatic growth in the use of use of discount and generic cigarettes by smokers over the past decade. Between 1988 and 1993, in 20 different American communities, the percentage of smokers who reported using discount/generic cigarettes increased by an average of $271 \%$, from $6.2 \%$ to $23.4 \%$. Our estimate of the use of discount and generic cigarettes is lower than national market share data based on unit sales for the same period. ${ }^{7}$ There are several possible reasons for this discrepancy. For example, the percentage of smokers who report consuming low-priced cigarettes does not directly equate with market share which is based on unit sales. As persons who smoke discount/generic cigarettes tend to smoke more cigarettes per day than those who use premium cigarettes, we would expect our prevalence-based estimates of discount/generic smokers to underestimate market share (percentage of unit sales). Additionally, the question we used to measure cigarette brand choice may not accurately reflect the variety of cigarette brands a smoker may consume over time. Some smokers may be embarrassed to report their use of discount or no name generic cigarette brands when asked about the brand they usually consume. Finally, our surveys were not designed to provide a national estimate of cigarette brand choice. Thus, to the extent that the COMMIT communities are unique and not representative of the United States as a whole, it is likely that our estimates of brand choices will be biased. However, the trend toward increased use of discount and generic cigarettes was evident in all 20 communities studied, suggesting that our findings are fairly robust. 
Use of low-priced cigarettes was more common among those who would be predicted to be sensitive to price; namely, those with lower incomes, higher levels of daily cigarette consumption, and those living in areas with higher average cigarette prices. This observation suggests that adult smokers are responding to price when making decisions about which brand of cigarette to smoke.

Age and race were also significant predictors of the use of discount/generic cigarettes. The use of low-priced cigarettes was most popular among middle-aged adults (aged 35-54 years) and least popular among younger adults (aged 25-34 years). This observation is consistent with those of Cavin and Pierce ${ }^{17}$ who found that, among California smokers, the use of low-cost cigarettes was more prevalent among middle-aged adults and less prevalent among teenagers and young adults.

This analysis did not consider the use of coupons or other economic incentives (merchandise) used to promote many premium cigarette brands popular with young smokers. ${ }^{18}$ To some extent, these incentives represent a rebate of expenditures and could be viewed as a reduction in price. ${ }^{19}$ Teenagers may also be less sensitive to price differences between premium and discount/generic cigarette brands compared with older smokers because they smoke a lot less than adults. It is also possible that young smokers may respond more to product imagery rather than price in deciding which brand to smoke.

The use of discount/generic cigarettes was significantly lower among black smokers compared with non-Hispanic whites. The explanation for this result is unclear. Since black smokers overwhelmingly smoke menthol cigarettes it is possible that available discount and generic menthol cigarettes are not comparable in quality or other important attributes to higher priced premium brands.

The lower rate of smoking cessation and higher levels of consumption seen among respondents using discount/generic cigarettes suggests that the availability of lower priced cigarettes has helped the cigarette industry retain smokers who might have otherwise reduced consumption or stopped smoking altogether. ${ }^{8}$ It seems reasonable to speculate that the availability of lower priced cigarettes may have slowed the rate of decline in cigarette use among adults in the United States over the past decade. In the absence of low-priced cigarettes, when prices went up, smokers had the option of either continuing to smoke, reducing the quantity smoked, or quitting. With the introduction of low-priced cigarettes, smokers had an additional option of switching from a full-priced cigarette to one lower in price. However, even if the price of premium cigarettes had not changed, the presence of lower priced cigarettes would have undoubtedly caused some smokers to shift from premium cigarette brands to low-priced cigarettes. Thus, it is difficult to know precisely the extent to which the availability of lower priced cigarettes has slowed the rate of decline in cigarette use over the past decade. The lower rate of cessation observed among smokers using low-priced cigarettes in this study does support the hypothesis that the arailability of low-priced cigarettes had some blunting effect on quitting behaviour. Given this observation, it is also likely that the price cut on premium brand cigarettes which occurred in spring summer 1993 similarly has contributed to a slowing of the decline in cigarette consumption. ${ }^{20}$ It appears that cigarette manufacturers, through their marketing and pricing practices, will do whatever is necessary to assure their profitability, which means keeping people smoking no matter what the cost.

Support for this research has been provided by the National Support for this research We Cancer Institute and the Robert at the 11 CO.LMIT research are indebted to our colleagues at the Information Managesites, the COMMIT coordinating Center, Infor Cancer Institute ment Services, Inc., and staff at the Nadonal Cancer Institute who planned and coordinated

Watson DS. Price theory and its uses. Boston, MassachuWiffin Company, 1972

settes: Houghton Mirful A theory of rationale addiction. $f$ Polit Econ 1988;96:675-99.

Lewit EM. U.S. tobacco taxes: behavioral effects and policy implication. Br f Addict 1988;84:1217-34

implication. Br figarette tax, economic welfare and social class patterns of smoking. Appl Econ 1987;19:355-65.

class patterns of smoking. Murphy KM. Governmental Schneider $L$, Kein $B$, Mulp information. F Law Econ regulation of cigar

6 Zimmerman C. Price value: how discount cigarettes captured 40

Mar:54-6.

7 Maxwell JC Jr. The Maxwell consumer report. Fourth-quarter and year-end 1993 sales estimates for the cigarette industry. Richmond, Virginia: Wheat First Securities, 10 February 1994.

8 Shapiro E. Trend toward quitting smoking slows as discoun cigarettes gain popularity. Wall Street fournal 1995 Apr 1:B1,B6.

Coalition on Smoking OR Health. Saving tives and raising revenue: the case for major increases in state and federal tobacco 1993.

10 American Medical Association. The Brown and Williamson American Medical Association. The Brown and (Editorial.) $¥ A M A$ 1995;274:256-8.

11 COMMIT Research Group. Community Intervention Tria for Smoking Cessation (COMMIT): summary of desi and intervention. I Natl Cancer Inst 1991;83:1620-8.

12 Mattson ME, Cummings KM, Lynn WR, et al. Evaluation plan for the community intervention trial for smoking cessation (COMMIT). Int $Q$ Commun Health Educ 1991; 11:271-90.

13 COMMIT Research Group. Community Intervention Tria for Smoking Cessation (COMMIT). I. Cohort results from a four-year community intervention. Am $\mathrm{F}$ Public Health 1995;85:183-92.

14 COMMIT Research Group. Community Intervention Trial for Smoking Cessation (COMMIT). II. Changes in adult $N$ cigarette sm

85:193-200. The Tobacco Institute. Washington, DC: The Tobacco Insti- N complication.

16 American Chamber of Commerce Researchers Association. American Chamber of Corter 1993 ACCRA cost of living index, quarterly repors

(3rd quarter) Louisville, Kentucky: ACCRA. 7 Cavin SW, Pierce JP. Low cost cigarettes and smoking behavior in California, 1990-1993. Am f Prev Med 1996, 12:17-21.

18 Coeytaux RR, Altman DG, Slade J. Tobacco promotion in the hands of youth. Tobacco Control 1995;4:253-7.

19 Sumner W, Dillman G. A fist full of coupons: cigarette continuity programmes. Tobacco Control 1995;4:245-52.

20 Shapiro E. New price move by Phillip Morris intensifies war. Wall Street fournal 1993 Jul 21:B1,B8. 